\title{
A new device for hydrogen production on demand with application to electric assist bike: description, production characteristics and basic control
}

\author{
Jocelyn Sabatier ${ }^{1}$, Fabrice Mauvy ${ }^{2}$, Jean-Louis Bobet ${ }^{2}$, Damien Mohedano ${ }^{3}$, Matthieu Faessel ${ }^{3}$, \\ Frédéric Bos $^{3}$ \\ ${ }^{1}$ Bordeaux University, IMS Lab., UMR 5218 CNRS, 351 Cours de la Libération, 33405 Talence - FRANCE \\ ${ }^{2}$ CNRS, ICMCB Lab, UPR 5026, 87 Avenue du Dr Albert Schweitzer, 33600 Pessac - FRANCE \\ ${ }^{3}$ Bordeaux University, TechnoShop Coh@bit platform, Bordeaux Institute of Technology, 15 Rue Naudet, 33750 \\ Gradignan - FRANCE \\ \{jocelyn.sabatier, jean-louis.bobet, damien.mohedano, matthieu.faessel,frederic.bos\}@u-bordeaux.fr, \\ \{fabrice.mauvy\}@icmcb.cnrs.fr
}

Keywords: Hydrogen, PEM fuel cell, production on demand, water hydrolysis, magnesium

\begin{abstract}
Using a magnesium-based hydrolysis reaction that spontaneously produces hydrogen with a high kinetic and a high efficiency, this paper proposes a solution to supply a PEM fuel cell that permits production on demand. This solution is an instrumented reactor that uses capsules with magnesium powder and that controls the hydrolysis reaction in order to maintain a constant pressure. The hydrogen produced by the reactor is used to feed a PEM fuel cell in which variable electric loads are applied. By solving both the hydrogen supply and storage problems, such a system is particularly suitable for light mobility applications.
\end{abstract}

\section{INTRODUCTION}

Urban travel covers a significant economic reality. The last mile represents almost $20 \%$ of the total cost of the freight value chain. In France, it accounts for about $20 \%$ of the traffic, occupies $30 \%$ of the road network and is responsible for $25 \%$ of greenhouse gas emissions (Roullé and Lorrillard, 2012). The last mile problem of goods and persons thus raises many essential issues - economic, environmental, societal and urbanistic - that the authorities are trying to solve with electric vehicle such as bicycle or tricycle. As the recharging of these means of transport is a lengthy process, dihydrogen $\left(\mathrm{H}_{2}\right)$ coupled with a fuel cell as a source of fuel is thus often considered.

Hydrogen mobility is seen by many as a solution for the future. Indeed, the modularity of hydrogen (used directly or indirectly via a fuel cell), its high combustion energy ( 3 times that of hydrocarbons) and its non-polluting nature make it a very promising fuel. However, three major problems hinder the large-scale development of this technology.

Environment: $95 \%$ of the hydrogen currently produced comes from steam reforming of natural gas which does not solve environmental problems. The production of hydrogen without an environmental impact therefore remains an important issue
Refueling: In a country such as France, there are only very few points where hydrogen refueling is possible.

Storage: Hydrogen can be stored under pressure or in liquid form, which in both cases causes storage safety and/or cost problems, or in solid form in hydrides, which solves the safety question but induces a large tank mass constraint. In any case, the volume of the tank will be larger than a tank of hydrocarbons.

The work described in this paper provides an answer in the area of electric assistance for bikes or tricycles or more generally for light mobility. In such applications, the hydrogen must be produced on demand, as the PEM fuel cell needs to consume it to produce electrical energy, to avoid any storage constraints. To reach this goal, the hydrogen is produced by the help of water hydrolysis. In order to control the reaction, a dedicated reactor was designed. This reactor has been implemented in a test bench to feed a PEM fuel cell associated to an electric load.

\section{CHEMICAL REACTIONS FOR HYDROGEN PRODUCTION}

In the present study, hydrogen gas is produced by hydrolysis reaction. One of the main advantage is that no additional energy is required (low temperature operation) and delocalized and rather pure hydrogen 
can be produced. Various materials have been used to perform hydrolysis: complex hydrides (Kojima et al, 2004), (Muir and Yao, 2011), metal (Huang et al, 2013), metal hydride (Uesugi et al, 2011), and intermetallics (Li et al, 2013) (Huang et al., 2014).

Magnesium metal was selected in this study for hydrogen production via hydrolysis due to its high electrochemical activity, low density, low cost, abundance and nontoxicity.

Magnesium reacts with water according to the following equation:

$$
\mathrm{Mg}+2 \mathrm{H}_{2} \mathrm{O}=\mathrm{Mg}(\mathrm{OH})_{2}+\mathrm{H}_{2} .
$$

However, the magnesium hydrolysis reaction is always blocked by the formation of a passive hydroxide layer $\operatorname{Mg}(\mathrm{OH})_{2}$ at the surface of the solid grains and cannot be carried out completely (maximum yield of 10 to $15 \%$ only). In order to improve the hydrolysis efficiency of $\mathrm{Mg}$, different additives and grinding processes have been investigated. The technical solution used here is described in details in (Awad et al, 2016) (Mauvy et $a l, 2017$ ). The resulting powder exhibits fast kinetics and $100 \%$ yield. Considering reaction (1), $1 \mathrm{~g}$ of magnesium powder (with above-mentioned additives) with $1.5 \mathrm{~g}$ (or $\mathrm{ml}$ ) of water produces 0.8771 (or $0.0789 \mathrm{~g}$ ) of dihydrogen, leading to a chemical energy of $9.03 \mathrm{~kJ}$. In the laboratory, the efficiency of this reaction is within 90 and $100 \%$ (depending on the additives used) (Awad et al, 2016).

\section{REACTOR}

\subsection{Description of the setup}

The reaction described by relation (1), is spontaneous (if prepared as explained in (Awad et al, 2016)) and only terminates when one of the two reagents (magnesium or water) is lacking.

For bike electric assistance fed with a PEM fuel cell, in order to avoid a constraining storage tank, hydrogen must be produced on demand, as the PEM fuel cell needs to consume it to produce electricity.

To control the kinetic parameters, an instrumented reactor was designed and is shown schematically in figure 1. A peristaltic pump (2) immersed in the water tank is used to supply a water flow proportional to the control voltage applied to the motor driver. This linearity between control voltage and water flow will facilitate the synthesis of the control law presented in section 4 . The water is stored in the compartmented tank (1) and the magnesium powder is contained in the separate capsule (3). According to (1), a stoichiometry ratio of 1.5 between mass of water and mass of magnesium is required. Through the nozzle (5), the water sprinkles the magnesium powder and hydrogen is produced. The hydrogen is evacuated via a non-return valve (6)into the water tank. The tank (1) thus acts as a buffer volume and allows the produced hydrogen to cool, inducing a partial condensation of the water vapor it contains. As reaction (1) is exothermic, the reactor was equipped with a heat-pipe cooling system (4). Two sensors (7) measure the pressure variations inside the tank (1) and inside the reaction chamber. A PT1000 probe was also implemented to measure the temperature of the reaction chamber. Two safety valves (8) were also mounted on the reactor.
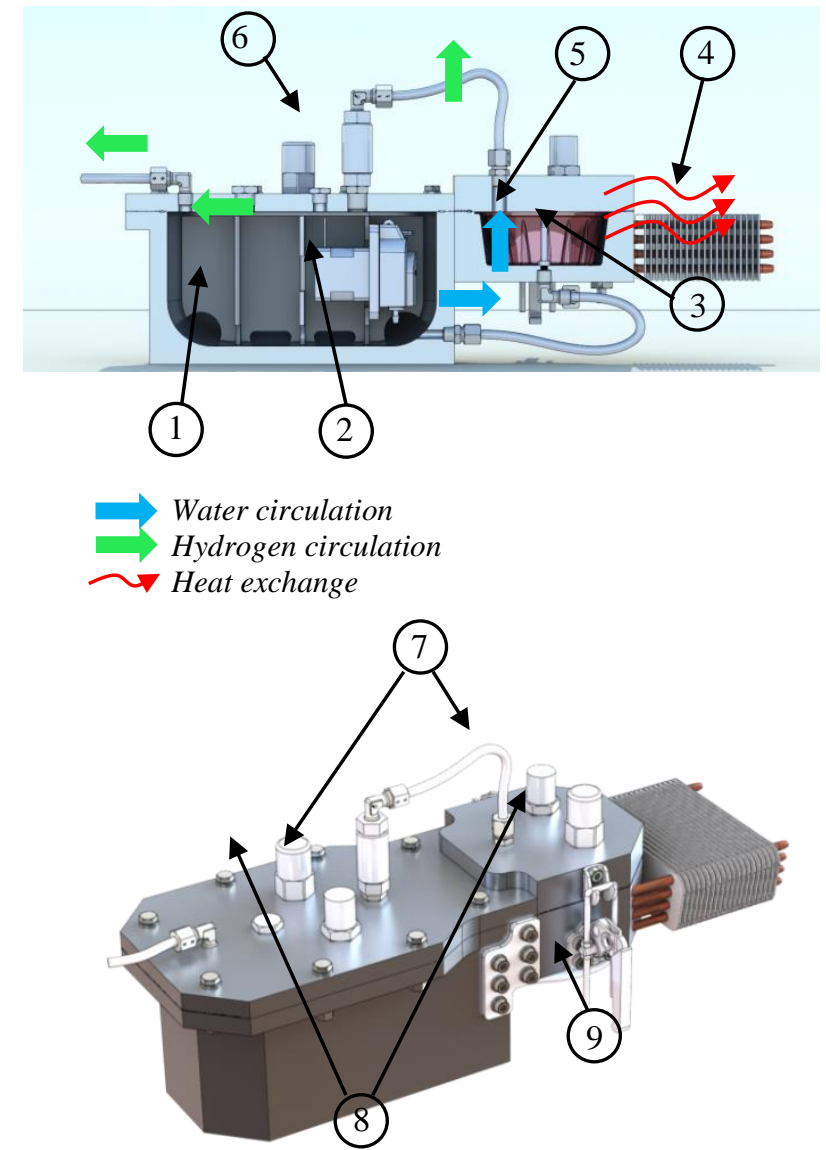

Figure 1: Reactor used to control the water hydrolysis that produces hydrogen: sectional view (up), general view (down)

\subsection{Tests without control}

The first tests of the $\mathrm{H}_{2}$ production system were done with a direct voltage control of the peristaltic pump (2) and with a capsule containing $10 \mathrm{~g}$ of magnesium powder. The variations in the voltage applied to the pump and the hydrogen pressure inside the reactor are shown in figure 2. This figure shows that the reactor is able to control the hydrogen production since the water injected when the pump is controlled is completely consumed, and the pressure no longer rises, meaning that the hydrolysis reaction 
has stopped. If water is injected again, the reaction is resumed and the pressure increases step by step.
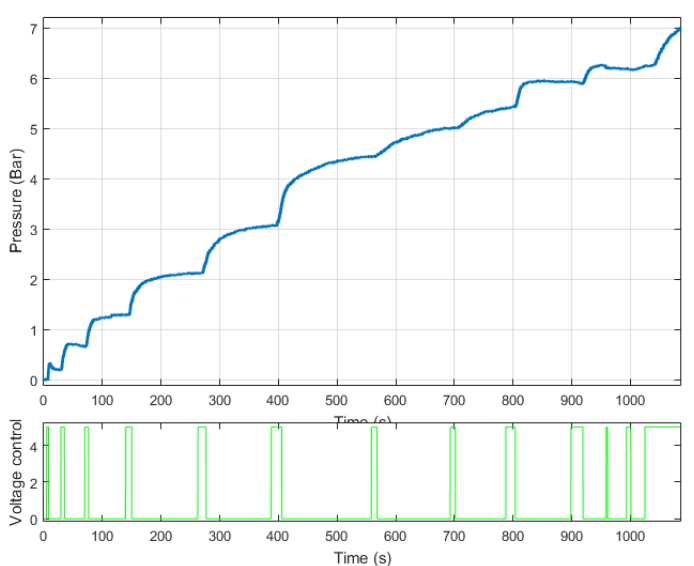

Figure 2: Pressure variation (top) resulting in voltage control of the pump (bottom)

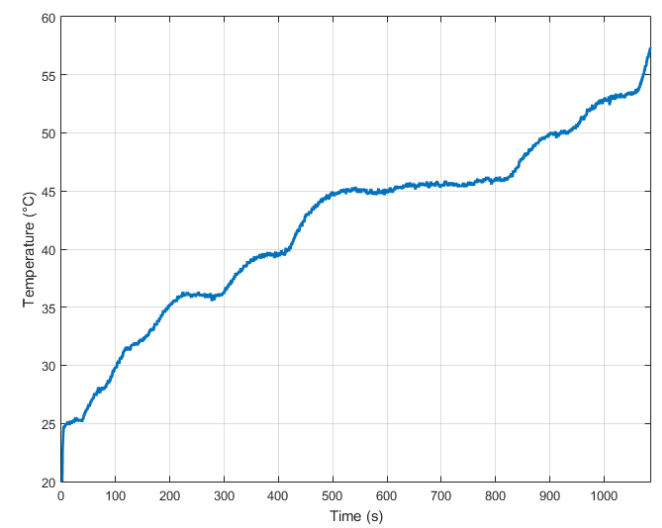

Figure 3: Temperature variation during the test

Due to :

- the proportionality between the injected water flow and the control voltage applied to the pump driver,

- the stoichiometry conditions imposed by reaction (1),

it is possible to define when all the magnesium of the capsule has been consumed and to create a fuel gauge.

Reactor chamber temperature variations are shown in figure 3 . This temperature analysis was completed by thermal imaging as illustrated by figure 4 . These figures highlight the efficiency of the heatpipe cooling system that reaches a high temperature during the test in comparison with the other parts of the reactor (strong heat dissipation of the cooling system). (a)

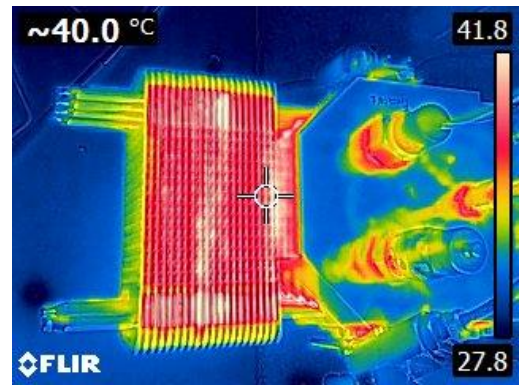

(b)

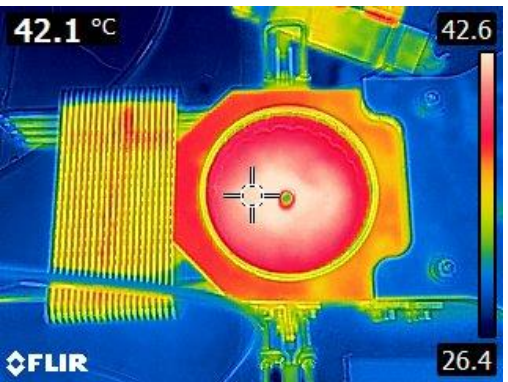

Figure 4: Thermal imaging of the reactor during the test and after the test, reaction chamber being open

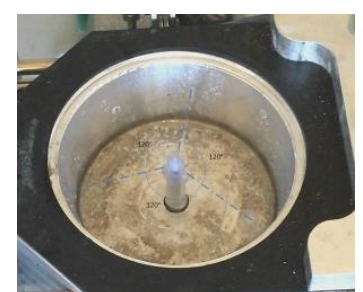

(a)

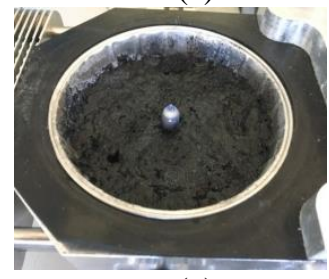

(c)

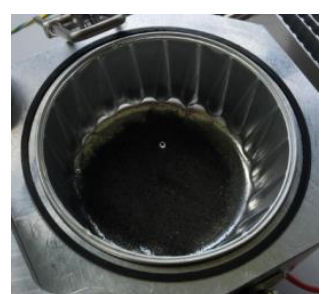

(b)

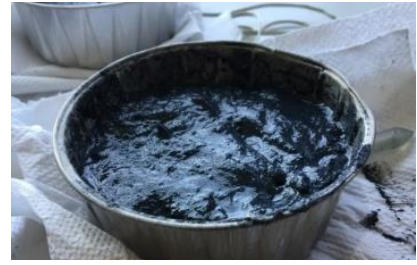

(d)
Figure 5 - Powder spray system (a), and capsule with magnesium powder (b), capsule containing the reaction products (c) and (d).

Figure 5 shows:

(a) the reaction chamber and the nozzle (5), without a capsule;

(b) the reaction chamber with a capsule filled with magnesium powder

(c) the capsule inside the reaction chamber at the end of the reaction

(d) the capsule outside the reaction chamber after the reaction. 
After the reaction, the capsule content is magnesium hydroxide which is a non-polluting and non-harmful substance (black color due to the additives).

\section{TEST BENCH}

\subsection{Description}

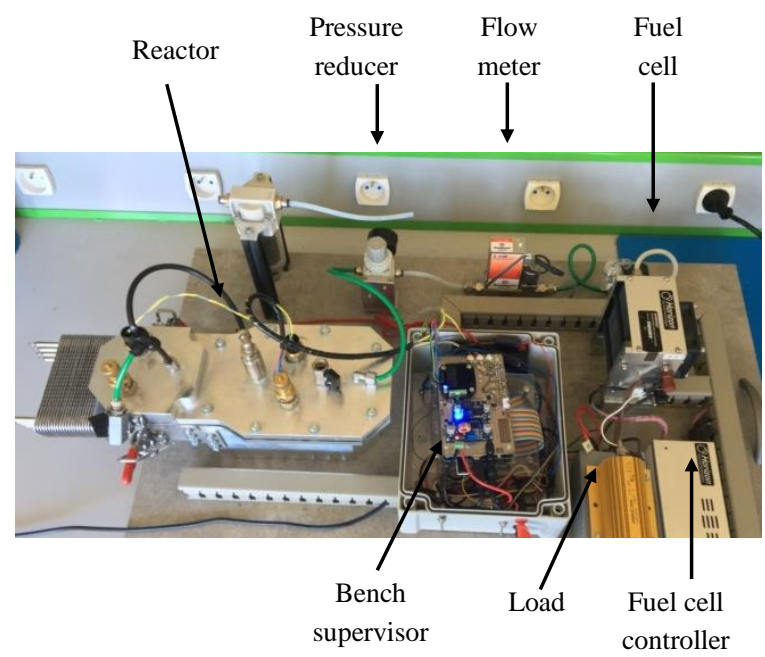

Figure 6 - Test bench with the reactor and the 100W PEM fuel cell

The reactor was integrated into the test bench described in figure 6, equipped with a 100W PEM type fuel cell. On this bench, the fuel cell is connected to a resistor (load) controlled in PWM mode. At the output of the reactor, the hydrogen pressure is reduced to 0.6 bar to be compatible with the fuel cell operating specifications. The hydrogen flow that supplies the fuel cell is also measured by a flowmeter. The bench supervisor measures the pressures and temperature inside the reactor, the hydrogen flow and also several electrical quantities at the fuel cell and the load terminals. The supervisor generates the PWM signal applied to the load, warns the operator when all the magnesium inside the reactor has been consumed, and manages several safety devices. Another goal of this supervision is to control the kinetics of the hydrolysis reaction, by regulating the water flow injected by the pump, through the control of the voltage $V(t)$ applied to the pump driver, in order to maintain the hydrogen pressure $P(t)$ inside the reactor at a reference value $P_{\text {ref }}(t)$, where $t$ is time. This is carried out by a control loop shown in figure 7.

\subsection{Dynamical behaviour analysis}

Prior to the design of the control law in figure 7 , the dynamical system linking the pressure $P(t)$ inside the reactor and the control voltage $V(t)$ applied to the pump driver must be modeled. Figure 2 shows the pressure variations when limited duration step input voltages are applied to the pump driver. This figure reveals that such a system is weakly non-linear: similar pressure behaviors are obtained in spite of variable step duration and whatever the operating pressure and temperature. A linear modeling approach was therefore adopted using a transfer function $H(s)$, where $s$ denotes the Laplace variable. Measures plotted in figure 8 , extracted from the curves in figure 3 , highlight that the pressure responses begin with a transport delay with respect to the pump control voltage (part 1). It is followed by a quasi-linear rise of the pressure (part 2) and finally there is a long memory relaxation after stopping the pump (part 3).

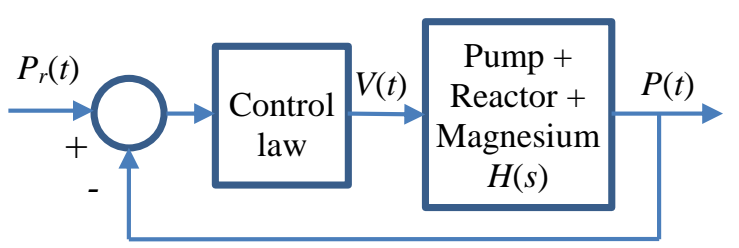

Figure 7 - Solution for the pressure control inside the reactor

A possible transfer function $H(s)$ is thus:

$$
H(s)=e_{\uparrow}^{-s T}[\frac{K_{1}}{s\left(\tau_{1} s+1\right)}+\frac{K_{2}}{\underbrace{\left(\tau_{2} s+1\right)}_{\text {Part } 2}}+\underbrace{\frac{K_{3}}{\left(\tau_{3} s+1\right)}}_{\text {Part } 3}]
$$

where $T$ (sec), is the model time delay, and where $K_{1}$ (bars/V) and $\tau_{\mathrm{I}}(\mathrm{sec}), i \in[1 . .3]$ are respectively gains and time constants.

Numerical values of the parameters in relation (2) can be evaluated for the various operating pressures considered as shown by figure 8 . They are obtained using a nonlinear optimization algorithm that minimizes the difference between the recorded data and the model output. The following inequalities were obtained:

$$
\begin{gathered}
3.8929 \times 10^{-3} \leq K_{1} \leq 1.9609 \times 10^{-2} \\
1.1188 \times 10^{-1} \leq K_{2} \leq 1.0061 \times 10^{2} \\
1.1142 \times 10^{1} \leq K_{3} \leq 1.4938 \times 10^{2} \\
4.4598 \leq \tau_{1} \leq 7.4150 \times 10^{1} \\
1.7927 \times 10^{1} \leq \tau_{2} \leq 2.2138 \times 10^{4} \\
1.7927 \times 10^{1} \leq \tau_{3} \leq 7.3709 \times 10^{4} \\
1 s \leq T \leq 9 s
\end{gathered}
$$

Comparisons between the system and the model responses obtained are shown in figure 8 and reveal that the models capture the dynamical behavior of the system well. 

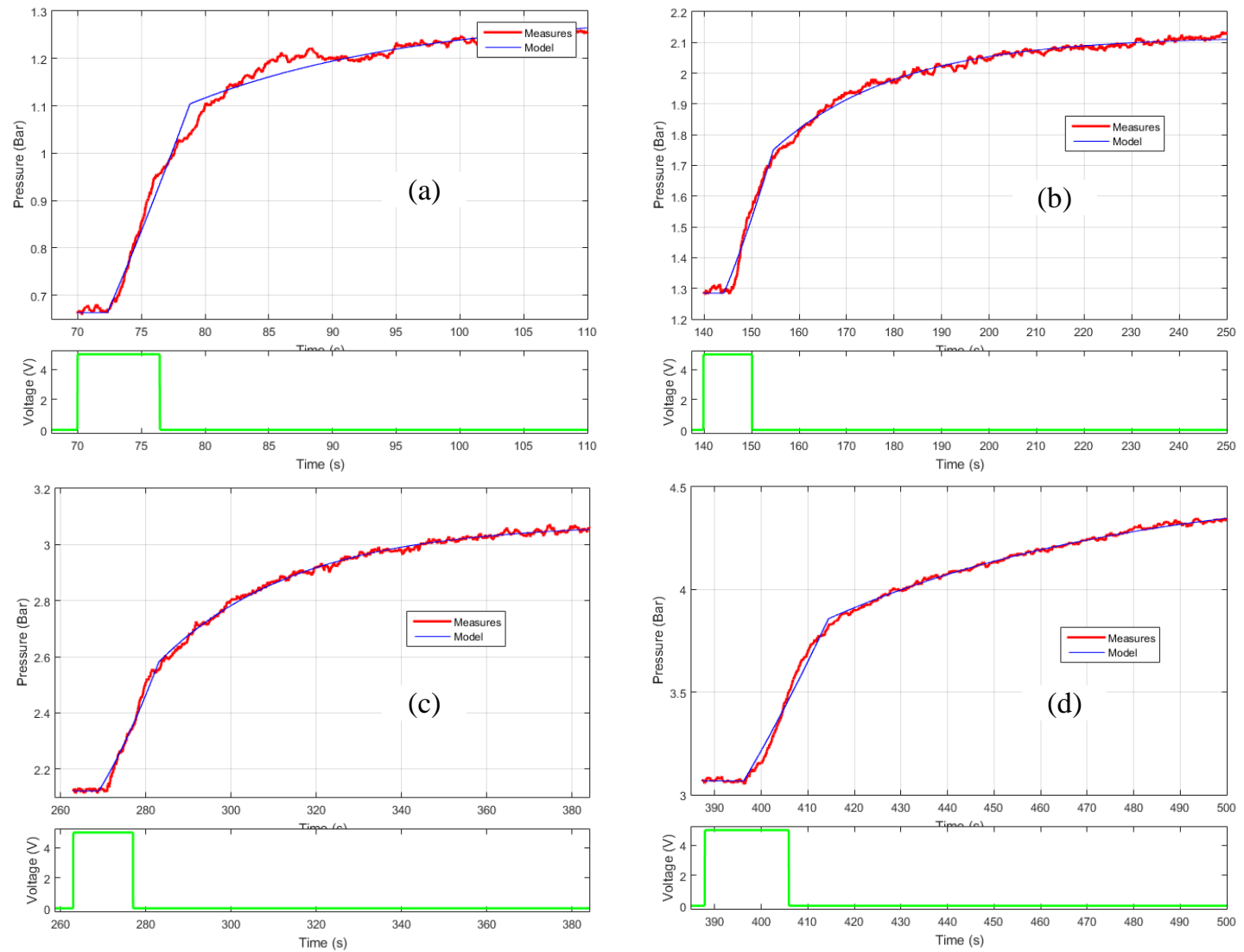

Figure 8 - Evolution of the pressure inside the reactor versus time and model response for different working conditions: (a) from 0.7 bar to 1.2 bar, (b) from 1.3 bar to 2.1 bar, (c) from 2.1 bar to 3 bar, (d) from 3 bar to 4.5 bar

\subsection{Pressure controller}

Due to the tradeoff imposed by time delays on a control law (Middleton, 1991) a linear robust control cannot lead to a large bandwidth feedback system for the pressure control. Thus, to take into account parametric variations (Utkin, 1993) highlighted in the previous section and to ensure a fast dynamical behavior, a switching controller was used for the reactor pressure control, the presence of a chattering phenomenon being the price to pay. This control law is shown in figure 9.

The controller $C(s)$ is designed to ensure closed loop stability and to control the period and the magnitude of the chattering phenomenon. This controller is defined by the transfer function $C(s)$ reported in relation $(10)$

$$
C(s)=\frac{100 s+1}{s / 5+1}
$$

As shown in figure 10, in which the Nyquist diagram of the transfer function $C(s) H(s)$ and of the describing function and of the relay nonlinearity are plotted, such a controller ensures closed loop stability and a limit cycle whose frequency is within the interval [0.07-
1.2] $\mathrm{rd} / \mathrm{s}$, depending on the parameters considered for $H(\mathrm{~s})$. In this frequency band, the gain of $H(\mathrm{j} \omega)$ is less than $-20 \mathrm{~dB}$, thus leading to a limit cycle magnitude close to 0.2 bar.

The controller $C(s)$, but also several other supervision functions (temperature, magnesium gauge, end of reaction detection, fuel cell on/off, load control, ...) are implemented with a National Instruments MyRio board. The sampling period $T_{e}$ of the supervision main loop and thus of the pressure control loop is chosen equal to $10 \mathrm{~ms}$. The sampling frequency is thus $628 \mathrm{rd} / \mathrm{s}$. This is more than 1000 times the controlled system bandwidth.

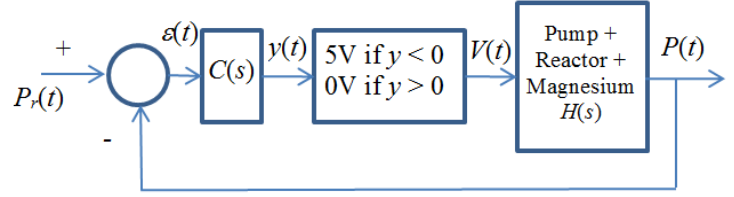

Figure 9 - Solution for the control of the pressure inside the reactor 


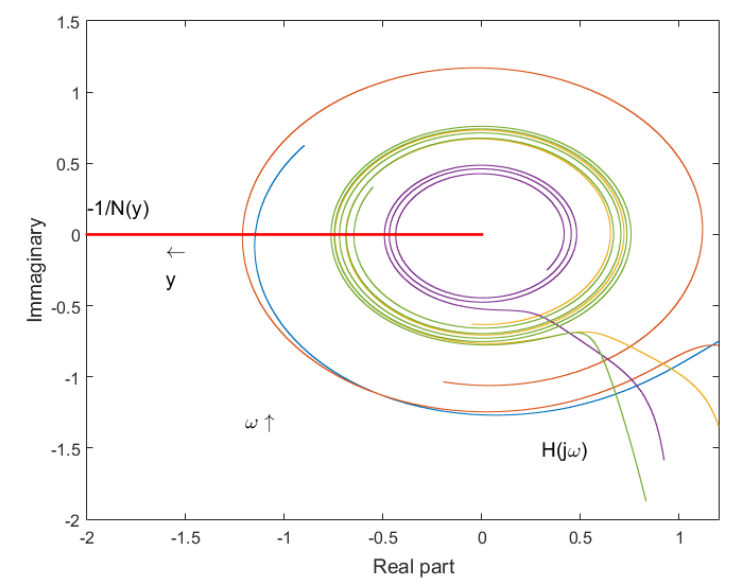

Figure 10 - Nyquist plot of the transfer function $C(s) H(s)$ and of the describing function of the relay nonlinearity.

The controller discretization can thus be done using the Euler approximation $\mathrm{s}=\left(1-z^{-1}\right) / T_{e}$. It thus defined by

$$
C(z)=\frac{9.955223 \mathrm{z}+-9.950248}{\mathrm{z}-9.950248} .
$$

\subsection{Results}

To evaluate the efficiency of the pressure control loop, a test with $15 \mathrm{~g}$ of magnesium powder was carried out. During the test, the pressure reference is set to 2.5 bars. The evolution of the pressure versus time is shown in figure 11. On this figure, the pump control voltage and the electrical power produced by the fuel cell are also depicted. Figure 12 shows the hydrogen flow produced by the reactor and figure 13 plots the reactor temperature variations.

These figures highlight that the pressure control loop was started about 25 seconds after the beginning of the test. The maximum voltage was then applied to the pump leading to a fast increase of the pressure inside the reactor (around $50 \mathrm{mbar} / \mathrm{s}$ ). At time $t=$ $100 \mathrm{~s}$, the reference pressure was reached and the control voltage went back to 0 . Without hydrogen consumption, the pressure remained stable.

The fuel cell is started at time $t=190 \mathrm{~s}$. A strong purge is created by the fuel cell management system (see figure 11) leading to a pressure decrease inside the reactor that is countered by the pressure closed loop. For proper fuel cell operation, the system generates purges and periodic short circuits (every 5 seconds alternately) that do not affect the pressure control (on the time interval [200s $-280 \mathrm{~s}]$. On the time interval [280s - 650s], a varying load is applied to the fuel cell. When the load increases, hydrogen consumption also increases (see figure 12). However, the pressure remains stable, thus demonstrating the efficiency of the pressure control loop. When the load decreases (at time 380s and 500s), a kind of overshoot appears. This phenomenon was assigned to an excess of water in the reactor when the hydrogen demand falls sharply, since the system and the control law do not allow this water to be withdrawn.

At time 630s, the reactor temperature decreases in spite of the pump control voltage being high. This means that all the powder has been consumed. To check it, the pump control voltage is forced at time 730 s and 780s. As no pressure increase appears, this confirms the end of the reaction. It should be pointed out that the noisy power signal in figure 11 is the result of purges and short circuits imposed on the fuel cell. The reactor temperature evolution versus time is shown by figure 13 . The temperature remains below $75^{\circ} \mathrm{C}$ and decreases when all the powder has been consumed (this signal thus informs about the end of the reaction).

\section{REACTOR BEHAVIOUR IN REAL OPERATION}

Given the satisfactory behavior of the prototype, the authors are currently mounting the prototype on the electric bike shown in figure 14. This electric bike was designed at the Bordeaux Institute of Technology and presented at the 2015 Intelligent Transport System ITS World Congress. It provides an electric assistance proportional to the power produced by the cyclist using pedals that capture the pedaling effort. As shown by figure 15, the electric power is provided by a kit mounted on the bike which incorporates a 100 W fuel cell.

\section{CONCLUSIONS}

In this research work, a solution to produce hydrogen on demand based on water hydrolysis using magnesium was presented. It involves a reactor whose internal pressure is adjusted by controlling the hydrolysis reaction. Tests on a bench fitted with a 100 W PEM fuel cell have demonstrated the technological potential of this solution for electric assistance applications in the field of light mobility.

In this first phase of tests, the reactor was designed to withstand a pressure of 25 bars, which makes it rather cumbersome. The authors are thus working on an improved, more ergonomic version, with more sophisticated control solutions for a better pressure control (overshoot suppression).

\section{ACKNOWLEGMENTS}

The authors acknowledge the AST society, the Aquitaine SATT, for the funding of the prototype presented in this paper in the form of the HELP maturation project. 
The authors also acknowledge the Bordeaux Institute of Technology team who designed the electric bike on which the reactor is currently installed (Leyney and Sabatier, 2016) during a project that was funded by Rordeanx ritv

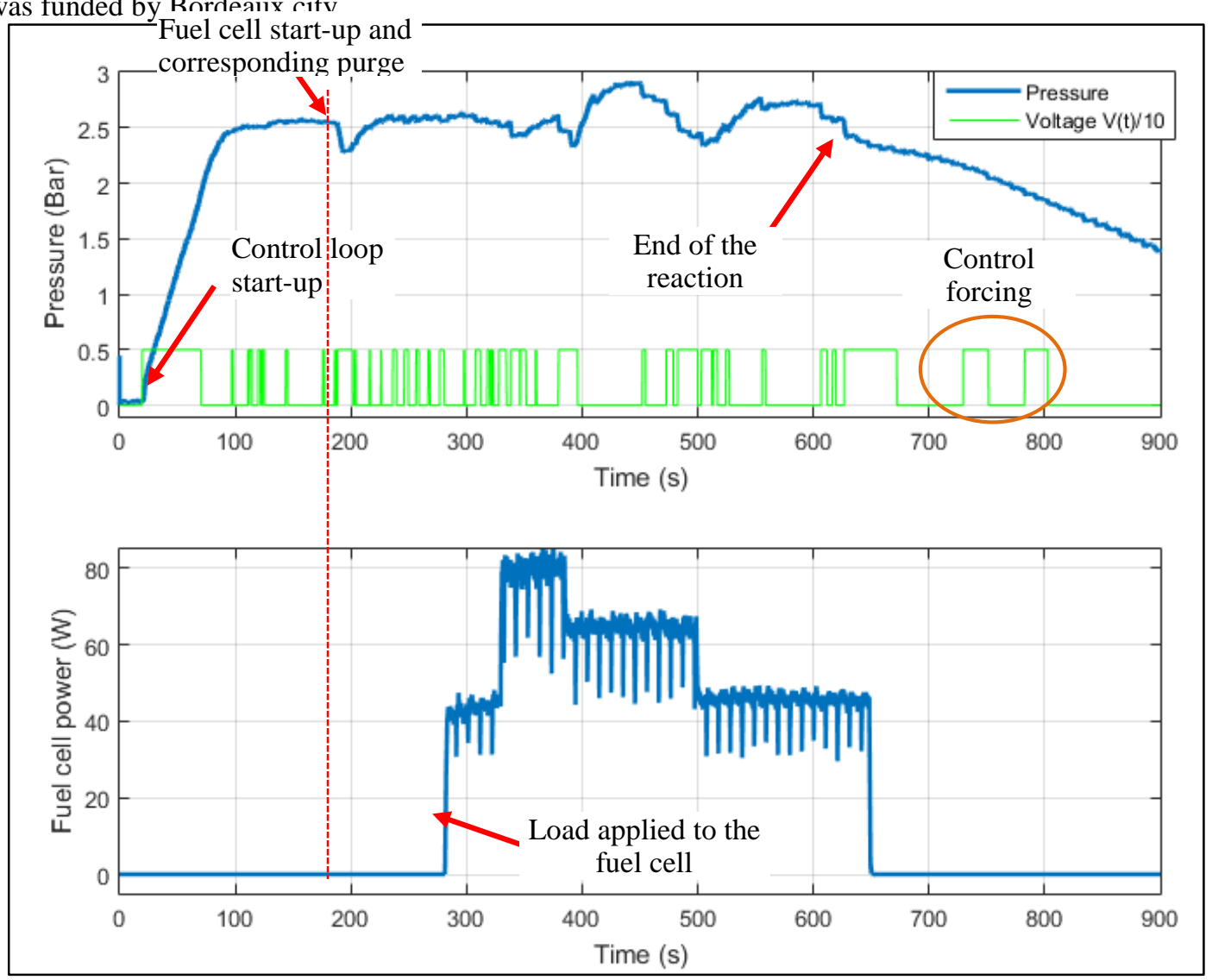

Figure 11 - Pressure variation inside the reactor and control voltage applied to the pump (up), electrical power produced by the fuel cell.
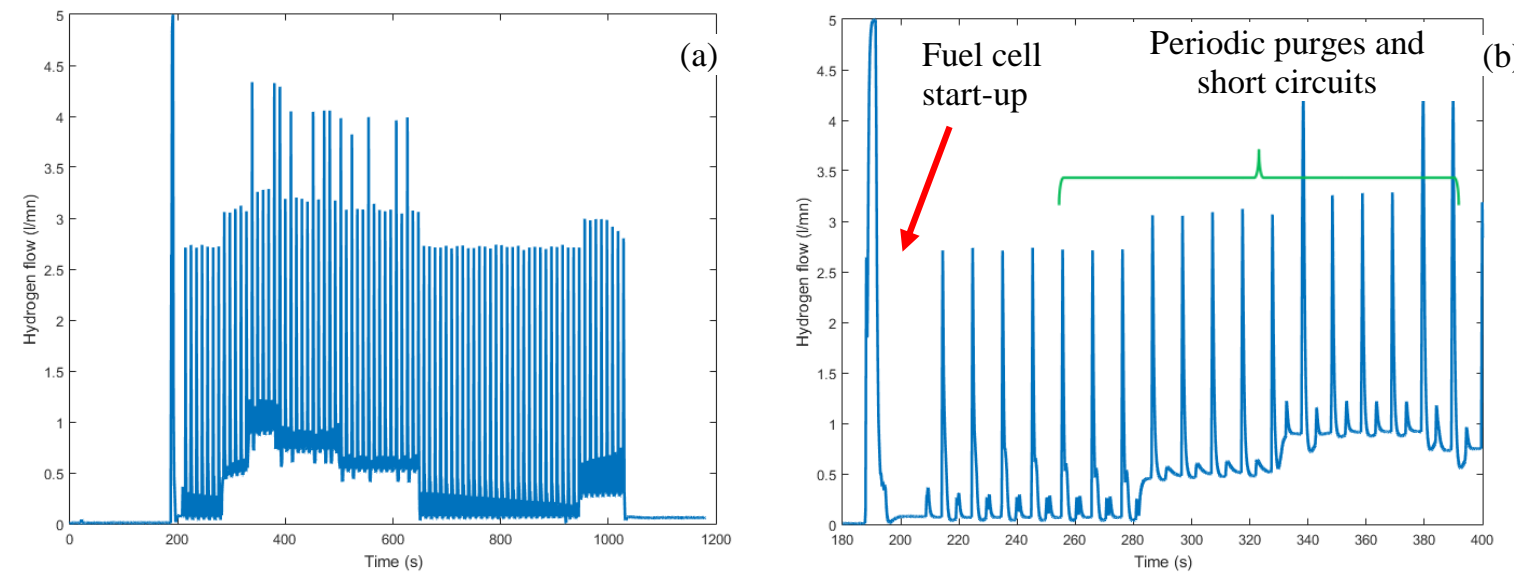

Figure 12 - Hydrogen flow produced by the reactor during the test (a) and zoom on the beginning of the test (b) 


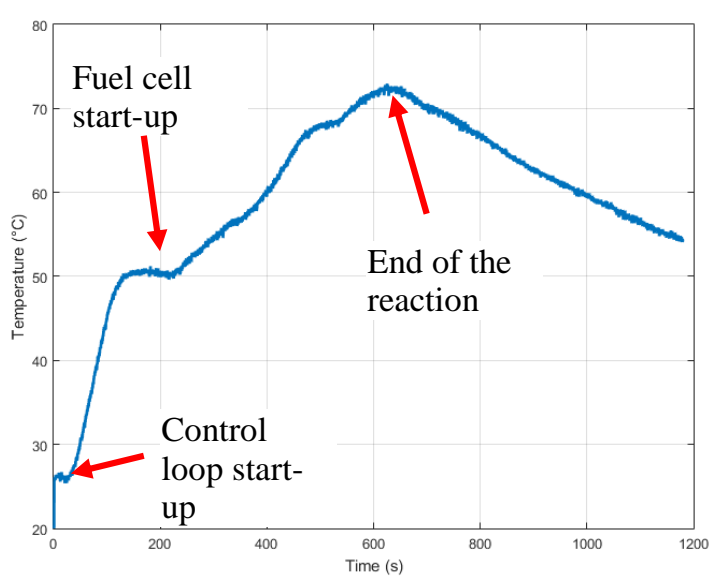

Figure 13 - Temperature inside the reactor during the test

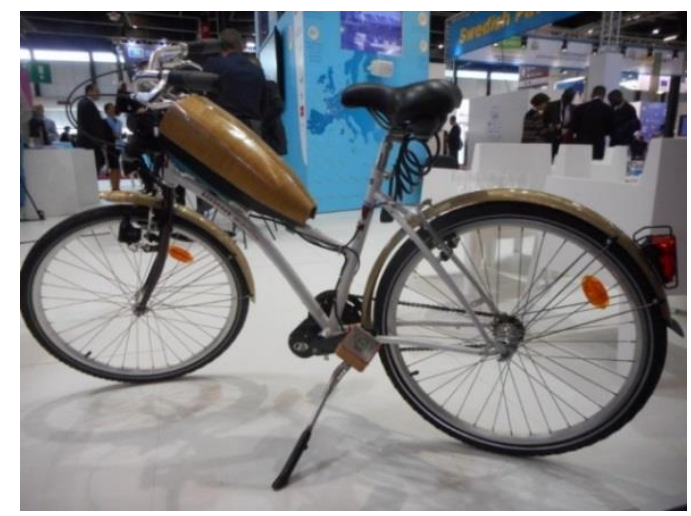

Figure 14 - Electrified Bordeaux city bike shown during the 2015 Intelligent Transport System (ITS) World Congress

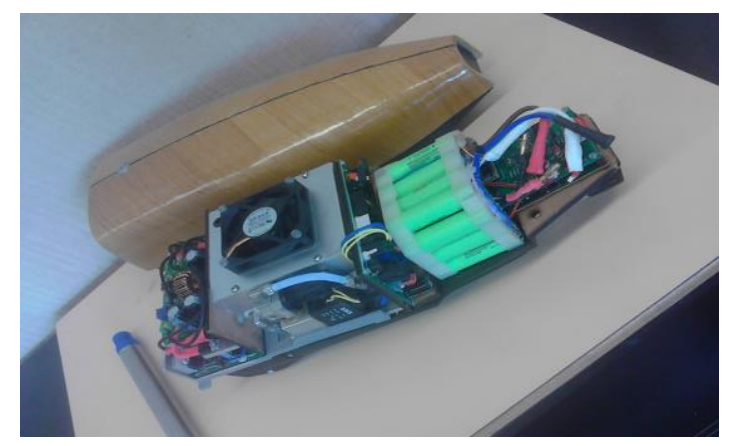

Figure 15 - Fuel cell and control kit installed on the bike. based hydrolysis reaction for fuel cell, Energy Vol 95, pp 175-186.

Huang X, Gao T, Pan X, Wei D, Lv C, Qin L, et al., 2013, A review: feasibility of hydrogen generation from the reaction between aluminum and water for fuel cell applications. J Power Sources, Vol 229, pp 133-40.

Huang JM, Ouyang LZ, Wen YJ, Wang H, Liu JW, Chen ZL, et al. (2014), Improved hydrolysis properties of $\mathrm{Mg}_{3} \mathrm{RE}$ hydrides alloyed with $\mathrm{Ni}$. Int $\mathrm{J}$ Hydrogen Energy Vol. 39, pp 6813-8.

Kojima Y, Kawai Y, Kimbara M, Nakanishi H, Matsumoto S., 2004, Hydrogen generation by hydrolysis reaction of lithium borohydride. Int J Hydrogen Energy, Vol. 29, pp 1213-7.

Leyney M, Sabatier J., Conception d'un kit d'assistance électrique pour la flotte des vélos de la ville de Bordeaux en versions purement électrique et hybridation à base de Pile à Hydrogène - GeSi Revue des départements de Génie Electrique \& Informatique

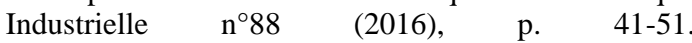
http://www.gesi.asso.fr/images/revue/complet/GESI88 .pdf

Li F, Sun L, Zhao J, Xu F, Zhou H-Y, Zhang Q-M, et al. (2013), Mechanisms of $\mathrm{H} 2$ generation for metal doped Al16M ( $11 / 4 \mathrm{Mg}$ and $\mathrm{Bi})$ clusters in water. Int $\mathrm{J}$ Hydrogen Energy, Vol. 38, pp 6930-7.

Mauvy F., Bobet J. L., Sabatier J., Bos F. (2017), Matériau à base de magnésium destiné à la production de dihydrogène ou d'électricité, INPI Patent application on October 6th, 2015 under the reference 1559, published on April, 13th, 2017 ref WO2017060368 A1

Middleton R.H., Trade-offs in linear control system design, Automatica, Vol. 27, pp 281-292, n 2, 1991

Muir SS, Yao X., 2011, Progress in sodium borohydride as a hydrogen storage material: development of hydrolysis catalysts and reaction systems. Int J Hydrogen Energy Vol. 36, pp 5983-97.

Roullé J. M., Lorrillard J., 2012, Pour un renouveau de la logistique urbaine, Note d'analyse 274 http://archives.strategie.gouv.fr/cas/content/notedanalyse-274-pour-un-renouveau-de-la-logistiqueurbaine.html.

Uesugi H, Sugiyama T, Nii H, Ito T, Nakatsugawa I., 2011, Industrial production of $\mathrm{MgH} 2$ and its application. $\mathrm{J}$ Alloy Compd, Vol. 509S, pp. 650-3.

Utkin V. I., 1993, Sliding Mode Control Design Principles and Applications to Electric Drives, IEEE Transactions on Industrial Electronics, Vol. 40, n 1, pp 23-36.

\section{REFERENCES}

Awad A. S., El-Asmar E, Tayeh T., Mauvy F., Nakhl M., Zakhour M., Bobet J. L. (2016), Effect of carbons (G and $\mathrm{CFs}), \mathrm{TM}(\mathrm{Ni}, \mathrm{Fe}$ and $\mathrm{Al}$ ) and oxides (Nb2O5 and $\mathrm{V} 2 \mathrm{O5}$ ) on hydrogen generation from ball milled $\mathrm{Mg}$ - 